\title{
H

\section{Review: Stinson, M. (Ed.). (2020). Dramatic encounters: Artistry, community and scholarship in drama teaching. Drama Queensland.}

\section{Peadar Donohoe}

The views and opinions expressed in the book reviews are those of the authors and do not necessarily reflect the position of SCENARIO.

Dramatic Encounters: Artistry, Community and Scholarship in Drama Teaching features stories of innovative student-focused productions and projects of teacher-artists from the state of Queensland, Australia. The comprehensive essays in this book illustrate the connections of teacher-artistry with the community and scholarship while empowering young people in the dramatic arts. All contributors are members of Drama Queensland, a non-profit professional association, that supports Drama educators in the K-12 and tertiary sectors, and also supports collaborations with the arts industry through projects involving companies, artists and arts venues.

Of the eight chapters, seven are essays of teacher-artist journey's outlining the scaffolding of their Process Drama projects, case studies and community productions. In the majority of instances, the projects led to performances for respective local communities. The projects ranged from the nature and benefits of Verbatim Theatre, Documentary Drama and other types of narrative enquiries; large scale projects that feature collaborations between schools, communities and, in some cases, professional artists; projects that embrace participants from a wide-range of cultures and backgrounds; work that supports students identified as special needs; a process drama initiative that details how The Mantle of the Expert could be employed in a classroom setting; the development and performance of an original student-realised and teacher-curated creative work; and the development of a locally responsive theatre work.

As a reader and theatre practitioner, who has developed process drama in education settings and Theatre in the Community projects, I found the detailed scaffolding from concept to formal public presentation of these student-centred projects riveting, instructional and inspirational. Alongside this, the journey towards each theatrical presentation was well written and detailed, which is a credit to the individual authors and writer and editor Madonna Stinson. I heartily recommend Drama Encounters to teachers who are looking for new, 
stimulating and creative ways to engage students in drama projects that strive to connect the school community to the wider community in order to create a bridge of shared understanding and respect. In order to provide the reader an impression idea of the content of the book, I will provide a brief synopsis of Chapter 2 .

Chapter 2, "Voices of the Valley: Verbatim and nostalgia in Senior Drama" by Emma Hill and Bruce Burton, details a Year-11 Verbatim Theatre unit, which ran for three years at a regional high school in Pioneer Valley, Queensland. Verbatim theatre, a form of documentary theatre, encourages drama students to acquire the skills to create and stage their own performances developed from the knowledge and understanding gleaned from their own community. The scripts are created from the transcription of interviews with people who are connected to a common event or subject. This allows theatre makers to explore events and themes through the words of people at the heart of them while providing the opportunity to build a sense of community between people.

The focus of this Verbatim project explored the history of the people who lived in and around Pioneer Valley, their perceptions of what is meant by the local motto 'Valley Pride' and what they would do if they lost their home, as happened to residents in the 1950's whose community was displaced by the development of an airport. Stories and artefacts were found for research purposes along with interviews from residents at the Nanyima Aged Care Centre who remembered what it was like to live in the valley before the airport development.

These elements served as the inspiration for drama classes that included elements such as biographical information, role-playing, use of song and music, the use of Brechtian techniques such as narration, presentational acting, pantomime, placards. These explorative classes helped the teacher and students find the narrative building blocks to develop a story arc, which in turn was fashioned into a script, that led to a production for the wider community. The project was deemed to have a profound impact on the audience, the performers and teacher-artists Hill and Burton. If any reader is considering a Verbatim Theatre project, I would highly recommend this essay with its well-detailed scaffolding of this project. It would serve as an instructive model to the aspiring teacher-artist.

As stated previously, there are eight chapters of the book but only seven of them are discourses on the scaffolding of student performances and projects. Chapter one reads like a preface and introduces the reader to the essays to come. At five pages long, it is incongruously short compared to the rest of the essays which clock in at approximately fifteen pages each. I would recommend that in future editions it be named as a preface and the section that is labelled as a preface, which is written by writers who are not the authors, be called the 
foreword. This would align with editorial norms where the forward is written by someone other than the author and the preface is written by the author.

The seven chapters that expound on the enriching value of student-led performances offer an excellent roadmap from inception to completion of each project. About half the essays are well-documented with pictures of the student performances. These pictures add greatly to the overall story, helping the reader visualise the process and final productions. However, the other half of the book has no pictures of students to help detail the process. It is a striking disparity and a small bit disappointing as the book begins with chapters that are wellsupported with photographic evidence of student engagement and then there is nothing for a stretch in the middle. A small note from the editor would have helped the reader to understand why there was a paucity of visual evidence.

Another small criticism is that not all acronyms are introduced consistently in the first instance. This may require the reader, especially international readers, to reference them online. A review of these for the next edition would be helpful for the unfamiliar and/or international reader.

These criticisms aside, I highly recommend this work to any aspiring teacher-artist. The thought, effort and heart that went into these projects is inspiring. As each essay details the scaffolding from inception to completion, I became so inspired by what I was reading, I daydreamed how I might organise versions of each of these process drama projects, wishing I had specific age groups to enact each one of them with.

In summation I would like to advise the interested reader that these essays will serve as stimulating reading and a well-detailed instructional roadmap to any teacher-artist who wants to create valuable and meaningful work for the wider community. There is no doubt that process drama and inspiring community theatre is alive and well in Queensland, Australia due to the efforts of Madonna Stinson and her colleagues. 